\title{
EDITORIAL
}

\section{Physical Therapy for Low Back Pain: What Is It, and When Do We Offer It to Patients?}

\author{
Timotby S. Carey, MD, MPH and Janet Freburger, PT, $\mathrm{PbD}$ \\ Cecil G. Sheps Center for Health Services Research, University of North Carolina at Chapel Hill, Chapel Hill, NC
}

Ann Fam Med 2014;99-101. doi: 10.1370/afm.1636.

$\mathrm{P}$ rimary care physicians are the main first-contact providers for patients with both acute and chronic low back pain in the United States. Although most patients presenting with new-onset back pain do well with a brief evaluation, reassurance, and symptomatic treatment, many studies have demonstrated that the minority of patients who develop chronic back pain are responsible for the large majority of health care and social costs. ${ }^{1-5}$ In the United States, health care costs for chronic low back pain have been rising, with some evidence suggesting this is due to an increase in the prevalence of chronic low back pain as well as more intensive use of tests and treatments. ${ }^{6,7}$ The health care and social costs for low back pain have been estimated to be between $\$ 100$ to $\$ 200$ billion annually with a majority of these costs due to lost wages and decreased productivity. ${ }^{8}$

Over the past 25 years, much low back pain research has focused on ways to predict which patients are going to progress to chronicity, with the goal of early intervention with targeted treatments that minimize the impact of the condition. Unfortunately, efforts have too often been unwieldy, expensive in their own right, and/or difficult to replicate. The article in this issue by Foster and colleagues represents an important incremental step in improving low back pain outcomes. ${ }^{9}$ The work builds on a prior randomized controlled trial demonstrating that stratified care management of low back pain patients by physical therapists improved low back pain outcomes in a cohort of patients treated in the United Kingdom. The current

Conflicts of interest: authors report none.

\section{CORRESPONDING AUTHOR}

Timothy S. Carey, MD, MPH

Cecil G Sheps Center for Health Services Research

CB 7590

University of North Carolina at Chapel Hill

Chapel Hill, NC 27599

timothy_carey@med.unc.edu work moves the approach from an efficacy setting to a real world setting where primary care physicians serve as the point of patient contact and stratification. The investigators demonstrated that this structured approach can benefit patients in typical practice settings. The demonstration of effectiveness of this care management approach provides additional support for testing such an approach in other settings, including the United States where state practice acts, third party payer requirements, and other barriers limit the patient's ability to directly seek the care of physical therapists. ${ }^{10}$ We use the term effectiveness to mean that the treatment protocol appears to have benefit for average patients seen in usual practice settings similar to where most patients are seen for the condition. Foster et al's treatment approach has 3 key characteristics:

- A brief stratification instrument built into an electronic health record template and implemented at the time of the primary care physician visit

- Risk strata matched treatment recommendations including referral of medium- and high-risk patients to selected physical therapists

- A physical therapy protocol that emphasizes maintaining function and avoiding time off work (medium- and high-risk patients) and the use of psychologically-informed physical therapy (high-risk patients)

The approach seems very straightforward. The stratification instrument is brief and can be incorporated into the visit without hiring extra staff. The decision points for the primary care physician are relatively simple: (1) screen for back pain red flags such as foot drop or warning signs of infection or malignancy (fever, weight loss); (2) after a screening history and physical, low-risk patients are provided advice on activity and medications, reassurance that further treatment is not necessary or beneficial, and that their prognosis is $\operatorname{good}_{i}$ (3) for medium- and high-risk patients, the patient is referred to a trained physical therapist. Interestingly, duration of symptoms 
is not part of the prognostic scale, yet studies have found that duration of symptoms is, not surprisingly, a predictor of future duration of spine symptoms. ${ }^{11,12}$ Clinicians choosing to use this scale should consider taking duration into account, especially if the back pain is functionally impairing.

The STarT Back screening tool has been validated in Great Britain, and validation in the United States would be appropriate to make sure that the cut points behaved similarly. Existing clinic personnel can conduct all of the steps of the assessment and treatment. The physical therapist receiving the referrals, however, needs to be trained in the protocols for the medium-risk and high-risk patients. In the STarT Back trial, therapists delivering the medium-risk protocol were trained for 3 days and those delivering the highrisk protocol were trained for 9 days. ${ }^{13}$ The protocol for the medium-risk patients (focus on restoring function, targeting physical signs/symptoms, and using exercise and manual therapy) likely reflects current care delivered by many physical therapists treating patients with low back pain. The high-risk protocol (psychologically informed physical therapy which uses elements of cognitive-behavioral therapy and incorporates patients beliefs, attitudes, and emotional responses into patient management), however, is in its infancy in the field of physical therapy. ${ }^{14}$ While some physical therapy clinicians and researchers are knowledgeable of this approach, many are not. There are also several barriers to implementing a biopsychosocial approach to physical therapy treatment in both entry-level physical therapy education and clinical practice, with current training in this approach extremely limited..$^{15}$ In psychologically-informed physical therapy, the physical therapist is not becoming a psychologist, but rather using elements of cognitivebehavioral therapy and biopsychosocial approaches to enhance the usual care approach. Although we are not specifically told in this article, non-evidence-based modality treatments sometimes used by physical therapists, such as traction, massage, and electrotherapy were not included in the protocols. ${ }^{13}$

Most of the benefit in the approach outlined by Foster and colleagues was found in the highest risk stratum. The low- and moderate-risk strata had little change in outcomes, and those identified were likely not of sufficient magnitude to be of policy importance. The outcome of the intervention in the high-risk group was about 2.5 points better on the Roland Scale compared to the baseline high-risk group, a change which has been demonstrated to be marginally clinically meaningful. ${ }^{16}$ Even in the high-risk group, there was little change on several outcomes measures. Most impressive was the reduction in the number of days off work, most prominent in the intermediate-risk group. The number of "appropriately referred" medium- and high-risk patients in the intervention group was also notable and suggests moderate success in the implementation of the stratification tool by primary care physicians. Modest cost savings were present in direct medical costs, with much greater cost savings to society through reduction in time off work. Changes in direct health costs are difficult to translate to the United States, since the UK approach to back pain is much more conservative than practice patterns in the United States. Sick leave policies are quite different from those in the United Kingdom, with many employees having only personal days, which combine sick leave and vacation, leading to less overall time off work for a given episode of back pain, compared with Europe.

Should we try to adopt such an approach in the United States? Our opinion is a qualified "yes." This approach represents a good candidate for broad evaluation and implementation. The costs of implementation are low, the approach is well documented, and the now widespread availability of electronic health records in the United States would allow for implementation of a stratification and referral process similar to that used in the UK study. However, prior to wide adoption, we recommend testing to assess whether the approach might need to be adapted somewhat to the US environment. A pragmatic clinical trial approach is one that would lend itself to such a test. US practices are increasingly part of large integrated delivery systems, and geographically dispersed practices could be assigned to intervention or control groups to avoid contamination of control groups by the intervention. Issues to be addressed in implementation include: What types of training for physical therapists will work best within the regulatory and licensure environment? Is particular guidance needed to reduce the likelihood of inappropriate imaging or opiate prescription by physicians? Are the cut points of the STarT Back tool similar in the different practice environments and for different patients (eg, those with shorter or longer symptom duration), and what are the outcomes on cost and time off work? The lag between referral and seeing a physical therapist was long in the United Kingdom, averaging 4 to 6 weeks, which would likely not be acceptable in the United States. In addition, there are some data to suggest that receipt of physical therapy within 2 to 4 weeks following a new primary care consultation reduces the risk of subsequent health care utilization, including the use of advanced imaging and injections. ${ }^{17,18}$ The very modest cost of implementation, and the similarity of such an approach to other short screening and stratification instruments currently in use in primary care, such as 
screening for alcohol misuse, ${ }_{1}^{19}$ or depression screening and evaluation protocols, ${ }^{20}$ suggest only minimal barriers to implementation. Practices could implement this approach with only modest expense and time. These advances don't solve our problems with the large disability burden and high costs of low back pain, but they represent a promising start.

To read or post commentaries in response to this article, see it online at http://www.annfammed.org/content/12/2/99.

Submitted January 3, 2014; submitted, revised, January 15; accepted January 15.

\section{References}

1. Deyo RA, Gray DT, Kreuter W, Mirza S, Martin BI. United States trends in lumbar fusion surgery for degenerative conditions. Spine (Phila Pa 1976). 2005;30(12):1441-1445, discussion 1446-1447.

2. Friedly J, Chan L, Deyo R. Increases in lumbosacral injections in the Medicare population: 1994 to 2001. Spine (Phila Pa 1976). 2007;32 (16):1754-1760.

3. Gray DT, Deyo RA, Kreuter W, et al. Population-based trends in volumes and rates of ambulatory lumbar spine surgery. Spine (Phila Pa 1976). 2006;31(17):1957-1963; discussion 64.

4. Luo X, Pietrobon R, Hey L. Patterns and trends in opioid use among individuals with back pain in the United States. Spine (Phila Pa 1976). 2004;29(8):884-890, discussion 891.

5. Weiner DK, Kim YS, Bonino P, Wang T. Low back pain in older adults: are we utilizing healthcare resources wisely? Pain Med. 2006;7(2):143-150.

6. Freburger JK, Holmes GM, Agans RP, et al. The rising prevalence of chronic low back pain. Arch Intern Med. 2009;169(3):251-258.

7. Mafi JN, McCarthy EP, Davis RB, Landon BE. Worsening trends in the management and treatment of back pain. JAMA Intern Med. 2013;173(17):1573-1581.

8. Katz JN. Lumbar disc disorders and low-back pain: socioeconomic factors and consequences. J Bone Joint Surg Am. 2006;88(Suppl 2): 21-24.
9. Foster NE, Mullis R, Hill J, et al. Effect of stratified care for low back pain in family practice (IMPaCT Back):a prospective populationbased sequential comparison. Ann Fam Med. 2014;12(2):102-111.

10. Ojha HA, Snyder RS, Davenport TE. Direct access compared with referred physical therapy episodes of care: a systematic review. Phys Ther. 2014;94(1):14-30.

11. Carey TS, Garrett JM, Jackman AM. Beyond the good prognosis. Examination of an inception cohort of patients with chronic low back pain. Spine (Phila Pa 1976). 2000;25(1):115-120.

12. Scheele J, Enthoven WT, Bierma-Zeinstra SM, et al. Course and prognosis of older back pain patients in general practice: a prospective cohort study. Pain. 2013;154(6):951-957.

13. Hill JC, Whitehurst DG, Lewis $M$, et al. Comparison of stratified primary care management for low back pain with current best practice (STarT Back): a randomised controlled trial. Lancet. 2011;378(9802): 1560-1571.

14. Main CJ, George SZ. Psychologically informed practice for management of low back pain: future directions in practice and research. Phys Ther. 2011;91(5):820-824.

15. Foster NE, Delitto A. Embedding psychosocial perspectives within clinical management of low back pain: integration of psychosocially informed management principles into physical therapist practicechallenges and opportunities. Phys Ther. 2011;91(5):790-803.

16. Beurskens AJ, de Vet HC, Köke AJ. Responsiveness of functional status in low back pain: a comparison of different instruments. Pain. 1996;65(1):71-76.

17. Fritz JM, Childs JD, Wainner RS, Flynn TW. Primary care referral of patients with low back pain to physical therapy: impact on future health care utilization and costs. Spine (Phila Pa 1976). 2012;37(25): 2114-2121.

18. Gellhorn AC, Chan L, Martin B, Friedly J. Management patterns in acute low back pain: the role of physical therapy. Spine (Phila $\mathrm{Pa}$ 1976). 2012;37(9):775-782.

19. Jonas DE, Garbutt JC, Amick HR, et al. Behavioral counseling after screening for alcohol misuse in primary care: a systematic review and meta-analysis for the U.S. Preventive Services Task Force. Ann Intern Med. 2012;157(9):645-654.

20. O'Connor EA, Whitlock EP, Beil TL, Gaynes BN. Screening for depression in adult patients in primary care settings: a systematic evidence review. Ann Intern Med. 2009;151(11):793-803. 